\title{
Monoclonal Antibodies to Gonococcal Outer Membrane Protein I: Location of a Conserved Epitope on Protein IB
}

\author{
By J. N. FLETCHER, K. ZAK, M. VIRJI AND J. E. HECKELS* \\ Department of Microbiology, University of Southampton Medical School, \\ Southampton General Hospital, Southampton SO9 $4 X Y$, UK
}

(Received 13 November 1985)

\begin{abstract}
Hybrid cell lines have been derived which produce monoclonal antibodies reacting with outer membrane protein I from Neisseria gonorrhoeae strain P9. The antibodies obtained showed variable reactivity with other strains but one antibody recognized an epitope present on all of the strains tested which expressed the protease sensitive protein IB. Purified IgG labelled with ${ }^{125}$ I was used in competitive radioimmunoassays with unlabelled antibody to investigate the spacial distribution of the epitopes recognized. Each pair of antibodies showed some degree of inhibition. The relative magnitude of inhibition suggested that the conserved epitope lies within a variable region containing other epitopes which determine the antigenic specificity of the protein. Western blotting of peptides derived by proteolytic digestion of protein IB revealed that the conserved epitope is located close to the chymotrypsin cleavage site within a $7000 M_{\mathrm{r}}$ surface exposed region of the molecule.
\end{abstract}

\section{INTRODUCTION}

Surface proteins of gonococci show considerable antigenic heterogeneity, not only between strains but also within a strain. Indeed, much of the success of the bacteria as pathogens may be attributed to their ability to switch expression of important virulence determinants (Heckels, 1986). Colonial variants of a single strain can express pili which differ in subunit molecular mass (Lambden et al., 1981a), amino acid composition and ability to attach to epithelial cells (Lambden et al., 1981 b). Similarly intrastrain variations in outer membrane protein II (P.II) are associated with alterations in antigenic specificity (Diaz \& Heckels, 1982), interactions with leucocytes (Swanson et al., 1975; Virji \& Heckels, 1986) and with epithelial cells (Lambden et al., 1979; Virji \& Everson, 1981). These variations, which were originally detected after growth in vitro, also occur during the course of the natural infection (Zak et al., 1984), suggesting that antigenic shift enables gonococci to adapt to an ever changing host environment. Antigenic variation of important virulence antigens is also a major obstacle to the development of an effective vaccine and focuses attention on conserved antigenic domains.

The major protein (P.I) is not subject to antigenic shift and is apparently essential to gonococcal viability since it functions as a porin, creating a hydrophilic diffusion channel allowing uptake of essential nutrients (Douglas et al., 1981 ; Lynch et al., 1984). P.I may also play an important role in gonococcal virulence since it can be transferred from the outer membrane (OM) into the host cell membrane (Blake \& Gotschlich, 1983), a mechanism which might have an important influence on interaction of gonococci with epithelial cells. Although P.I differs between strains and the differences are responsible for serotype specificity (Sandstrom et al., 1982), structural studies suggest that some domains are more widely shared (Swanson, 1979; Sandstrom et al., 1982) and that only a limited number of major classes of P.I exist. This report

\footnotetext{
Abbreviations: OM, outer membrane(s); PMSF, phenylmethanesulphonyl fluoride; TLCK, $N \alpha$-p-tosyl-lysine chloromethyl ketone; TPCK, $N$-tosyl-L-phenylalanine chloromethyl ketone.
} 
describes the production of monoclonal antibodies to P.I and their use in detecting conserved determinants present on the surface of large numbers of gonococcal strains.

\section{METHODS}

Bacterial strains and growth conditions. $N$. gonorrhoeae and $N$. meningitidis were grown on proteose peptone agar (Diaz \& Heckels, 1982) with the addition of hypoxanthine $\left(3.2 \mu \mathrm{g} \mathrm{ml}^{-1}\right)$ and uracil $\left(8 \mu \mathrm{g} \mathrm{ml}^{-1}\right)$, at $37^{\circ} \mathrm{C}$ in an atmosphere of $5 \%(\mathrm{v} / \mathrm{v}) \mathrm{CO}_{2}$ for $16-20 \mathrm{~h}$. Colonial variants of $N$. gonorrhoeae strain $\mathrm{P} 9$ have been described previously (Lambden et al., 1979). In these studies the Pil- P.II- variant P9-1 and the Pil- P.IIb ${ }^{+}$variant P9-16 were used. Fresh clinical isolates of $N$. gonorrhoeae and $N$. meningitidis were from sources previously described (Zak et al., 1984; Diaz et al., 1984). N. lactamica strains were from Dr C. Ison, St Mary's Hospital Medical School, London, and commensal Neisseria from Dr A. Johnson, Clinical Research Centre, Northwick Park, Harrow. Other Gram-negative bacteria were obtained as fresh isolates from the Public Health Laboratory, Southampton General Hospital, and grown on the same medium at $37^{\circ} \mathrm{C}$ for $16 \mathrm{~h}$.

$O M$ antigens. $O M$ vesicles were prepared by extraction of gonococci with lithium acetate followed by differential centrifugation (Heckels, 1977). Lipopolysaccharide (LPS) was prepared by phenol/water extraction (Lambden \& Heckels, 1982). All preparations were free from pilin by SDS-PAGE. Protein concentrations were determined by the Lowry method.

Enzyme-linked immunoassay ( $E L I S A)$. Polystyrene microtitre trays were coated with $\mathrm{OM}$ at a concentration of $1 \mu \mathrm{g}$ protein $\mathrm{ml}^{-1}$ in $0.1 \mathrm{M}-\mathrm{NaHCO}_{3}, \mathrm{pH} 9.5(100 \mu \mathrm{l})$ (Lambden \& Heckels, 1982), or with purified LPS at $1 \mu \mathrm{g} \mathrm{ml} \mathrm{m}^{-1}$ in $0.9 \% \mathrm{NaCl}$ containing $20 \mathrm{mM}-\mathrm{MgCl}_{2}$, at $37^{\circ} \mathrm{C}$ for $16-24 \mathrm{~h}$. After being washed plates were incubated at $37^{\circ} \mathrm{C}$

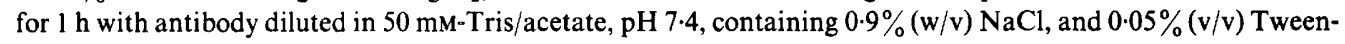
20 (Tris/Tween buffer) containing $1 \%(w / v)$ (BSA) (Fraction V; Sigma). The plates were washed and then incubated at $37^{\circ} \mathrm{C}$ for $1 \mathrm{~h}$ with rabbit anti-mouse IgG peroxidase conjugate (Miles) at a final concentration of $1: 4000$. After washing with $0.9 \%(\mathrm{w} / \mathrm{v}) \mathrm{NaCl}$ containing $0.05 \%(\mathrm{v} / \mathrm{v})$ Tween-20, the substrate [a solution of $3.6 \mathrm{mg}$ $3,3^{\prime}, 5,5^{\prime}$-tetramethylbenzidine (Miles) $\mathrm{ml}^{-1}$ in $0 \cdot 1 \mathrm{M}$-sodium acetate buffer, $\mathrm{pH} 6 \cdot 0$, containing $0 \cdot 01 \%(\mathrm{v} / \mathrm{v})$ of 100 volumes $\mathrm{H}_{2} \mathrm{O}_{2}$ ] was added and incubated at room temperature. The reaction was stopped by the addition of $1 \mathrm{M}$ $\mathrm{H}_{2} \mathrm{SO}_{4}$ and the $A_{450}$ determined in a Titertek Multiscan ELISA reader (Flow Laboratories). ELISA units were recorded as the antibody dilution which would give an increase in $A_{450}$ of $0.1 \mathrm{~h} \mathrm{~h}^{-1}$.

SDS-PAGE and Western blotting. Whole-cell bacterial lysates were subjected to SDS-PAGE at a concentration of $5-10 \mu \mathrm{g}$ protein per track on gels $(1 \times 160 \times 110 \mathrm{~mm})$ containing linear gradients of $10-25 \%(\mathrm{w} / \mathrm{v})$ acrylamide with a constant acrylamide: bisacrylamide ratio of 38:5:1 (Heckels, 1981). Low molecular mass peptides were separated on gels containing linear gradients of 10-18\% acrylamide with an acrylamide: bisacrylamide ratio of 19.2:1 and incorporating $7 \mathrm{M}$-urea (Hashimoto et al., 1983). Separated proteins were directly detected with PAGEBlue $83(\mathrm{BDH})$ or by silver staining (Merril et al., 1981) or were transferred to nitrocellulose sheets for immunological detection.

Separated proteins were electrophoretically transferred to nitrocellulose sheets (BA85; Schleicher \& Schull), using $20 \mathrm{mM}$-Tris $/ 150 \mathrm{mM}$-glycine buffer, $\mathrm{pH} 8 \cdot 3$, containing $20 \%(\mathrm{v} / \mathrm{v}) \mathrm{CH}_{3} \mathrm{OH}$ as described by Towbin et al. (1979) but with the addition of SDS to $0.1 \%(\mathrm{w} / \mathrm{v})$. Preliminary experiments showed that the presence of SDS in the transfer buffer was essential for adequate transfer of P.I. After blocking with BSA, sheets were sequentially reacted with monoclonal antibody and ${ }^{125}$ I-labelled Protein A. Immunological reactivity was detected by autoradiography (Virji \& Heckels, 1983).

For screening of hybridoma culture supernatants a sample of OM containing $200 \mu \mathrm{g}$ protein was subjected to SDS-PAGE as a single $115 \mathrm{~mm}$ wide well. After transfer to nitrocellulose, $3 \mathrm{~mm}$ wide strips were cut and each reacted with a different culture supernatant then treated as above. The antigens reacting with each antibody were identified by reference to autoradiographs of lysates of whole cells which had been surface labelled with ${ }^{125}$ I and transferred to nitrocellulose as side strips of the original gel.

Production and characterization of monoclonal antibodies. Hybridoma secreting anti-P.I antibodies used in these studies were obtained using immunization schedules described previously (Virji et al., 1983) and used mixtures of live gonococci comprising strain P9 and fresh isolates SU50 and SU72, each of which expressed P.IB. The general methods used for the production of hybrid cell lines have previously been described (Virji et al., 1983). Briefly, spleen cells from immunized BALB/C mice were fused with the NS-1 myeloma cell line in the presence of $50 \%$ (w/v) polyethyleneglycol-4000 (Merck). Initial screening of hybridoma supernatants was done by ELISA using purified OM and LPS from strain P9-1 as antigens. Those supernatants which reacted with OM but not LPS were further screened by ELISA, using purified OM from four other strains. Antibodies which reacted with more than one strain were further analysed by Western blotting. Hybridoma producing antibodies reacting with a variety of OM proteins were identified by this procedure and those of interest were cloned by limiting dilution. Clones were expanded and approximately $10^{7}$ cells were injected intraperitoneally in pristane-primed BALB/C mice for the production of ascitic fluids containing high concentrations of monoclonal antibodies. The specificity of antibodies 
present in ascitic fluid was confirmed by Western blotting. The immunoglobulin subclass of the antibodies was determined by ELISA using rabbit anti-mouse subclass specific antisera (Virji et al., 1983).

$S$ creening of bacterial strains for reactivity with anti-P.I antibodies. Anti-P.I monoclonal antibodies were screened for reactivity with a limited number of gonococcal strains by ELISA, using purified OM as antigens as described above. Larger numbers of bacterial strains were screened by 'dot blotting' of whole-cell bacterial lysates essentially as described by Virji \& Heckels (1983). Bacterial suspensions $(3 \mu \mathrm{l})$ in PBS were spotted onto nitrocellulose sheets, dried and lysed in the presence of Nonidet P-40. After blocking with 3\% BSA, the sheets were reacted with a $1: 100$ dilution of ascitic fluid for $1 \mathrm{~h}$ and washed, and antibody binding was detected with ${ }^{125} \mathrm{I}$-labelled Protein A.

Proteolytic sensitivity of P.I in different gonococcal strains. Gonococci were suspended in Dulbecco's complete phosphate-buffered saline, $\mathrm{pH} \mathrm{7.3} \mathrm{(Oxoid)} \mathrm{to} \mathrm{an} A_{550}$ of 1.0 (corresponding to $0.5 \mathrm{mg}$ protein $\mathrm{ml}^{-1}$ ) and mixed with an equal volume of TLCK $\alpha$-chymotrypsin (Sigma) in the same buffer $\left(250 \mu \mathrm{g} \mathrm{ml}^{-1}\right)$ or an equivalent volume of buffer alone. The suspensions were incubated at $37^{\circ} \mathrm{C}$ for $30 \mathrm{~min}$ when the reaction was stopped by the addition of PMSF to $1 \mathrm{mM}$. Samples were subjected to SDS-PAGE and the proteolytic sensitivity of P.I was determined by comparison of adjacent tracks from the same strain with and without chymotrypsin treatment.

Purification of antibodies and ${ }^{125}$ I labelling. Monoclonal antibodies of IgG class were purified by Protein A affinity chromatography as described previously (Virji et al., 1983) with minor modifications. Ascitic fluid was

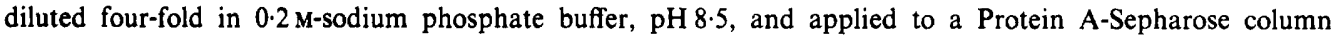
equilibrated in the same buffer. The column was washed with $0.02 \mathrm{M}$-sodium phosphate buffer and Ig eluted with $0.2 \mathrm{M}$-sodium citrate, $\mathrm{pH} 4$. Samples containing antibody were immediately neutralized using $5 \mathrm{M}-\mathrm{NaOH}$ and dialysed against PBS. Purified monoclonal $\mathrm{Ig}$ were labelled with $\mathrm{Na}^{125} \mathrm{I}$ and Iodogen (Pierce). Unreacted isotope was removed by chromatography on Sephadex G-25 to yield a product with a specific activity range of $22-$ $37 \mathrm{kBq} \mathrm{\mu g}^{-1}$. The preparations of Ig were monitored for reactivity against OM antigens by ELISA after each manipulation.

Radioimmunoassay and competitive binding experiments. Polystyrene microtitre plates were coated with purified OM from variant P9-1 under the conditions used for ELISA. Serial dilutions of ${ }^{125}$ I-labelled monoclonal antibody in Tris/Tween buffer were added in $100 \mu \mathrm{l}$ volumes to antigen-coated wells and incubated at $37^{\circ} \mathrm{C}$ for $1 \mathrm{~h}$. Plates were washed and the bound antibody was solubilized in $1 \%(\mathrm{w} / \mathrm{v})$ SDS in $0.1 \mathrm{M}-\mathrm{NaOH}$ and quantified by gamma counting (Virji et al., 1983). The avidity of antibody binding was determined from Scatchard plots as described by Frankel \& Gerhard (1979).

For competitive binding experiments serial dilutions of ascitic fluids or purified Ig in Tris/Tween buffer were incubated in antigen-coated wells for $1 \mathrm{~h}$ at $37^{\circ} \mathrm{C}$. Then the minimum amount of ${ }^{125} \mathrm{I}$-labelled antibody required for saturation binding was added to each well and incubation was continued for a further period of $1 \mathrm{~h}$. The plates were washed and bound radioactivity was determined by gamma counting. The unlabelled homologous antibody was included as a positive control for competitive inhibition. All assays were done in triplicate. The results were expressed as percentage inhibition of binding of ${ }^{125} \mathrm{I}$-labelled antibody. Percentage inhibition $=100 \times[1-$ (c.p.m. bound in the presence of unlabelled antibody $\div$ c.p.m. bound in the absence of unlabelled antibody)].

Detection of epitopes recognized by monoclonal antibodies on proteolytic fragments of P.IB. Purified OM from the P.II- variant P9-1 were suspended in PBS at a concentration of $1 \mathrm{mg}$ protein $\mathrm{ml}^{-1}$ and either TPCK trypsin or TLCK $\alpha$-chymotrypsin (Sigma) was added to give a final enzyme: protein ratio of $1: 20$. The tubes were incubated at $37^{\circ} \mathrm{C}$ and samples were removed at intervals. The reaction was stopped by the addition of SDS-PAGE dissociating buffer containing $2 \mathrm{mM}$-PMSF followed by heating to $100^{\circ} \mathrm{C}$ for $5 \mathrm{~min}$. Controls were done by incubating $O M$ in the absence of enzyme, and by adding PMSF before the enzyme, to obtain an effective zero incubation time. Proteolytic fragments were separated by SDS-PAGE, transferred to nitrocellulose and reacted with monoclonal antibody. In some experiments proteolysis was terminated by the addition of PMSF to $1 \mathrm{mM}$ and the incubation mixture was centrifuged in a Beckman Airfuge ultracentrifuge at $100000 \mathrm{~g}$ for $30 \mathrm{~min}$. The soluble and membrane fractions were separately subjected to SDS-PAGE.

\section{RESULTS}

\section{Properties of P.I reactive antibodies}

The aim of the current study was to obtain monoclonal antibodies which recognized widely distributed epitopes on P.I rather than unique 'type-specific' determinants. Accordingly the immunization strategy utilized OM from three strains and hybridoma were only selected for further study if they reacted in ELISA with more than one strain. The nature of the antigen recognized was then determined by reacting culture supernatants on Western blots of OM from strain P9. Five hybridoma which reacted with P.I were selected and antibodies produced by growth of the cloned hybrids in ascites were used for more detailed studies (Table 1). The 


\title{
Table 1. Reactivities of anti-P.I monoclonal antibodies
}

\begin{abstract}
Monoclonal antibodies raised against P.I were screened against purified OM preparations from several gonococcal strains by ELISA. Results are mean titres from three assays and are expressed as titre $x$ $10^{-6} ;-$ represents a titre $<0 \cdot 01$. The isotype of each antibody was also determined by ELISA as described in Methods. Avidity constants were determined by the method of Frankel \& Gerhard (1979); ND, not determined.
\end{abstract}

\begin{tabular}{cccccccc} 
& & & \multicolumn{4}{c}{ Reactivity of strain: } \\
\cline { 5 - 7 } Antibody & Isotype & Avidity & P9 & SU50 & SU62 & SU70 & SU72 \\
SM20 & $\gamma 2 \mathrm{a}$ & $1.2 \times 10^{8} \mathrm{M}^{-1}$ & 5 & - & - & - & - \\
SM21 & $\gamma 2 \mathrm{a}$ & $3.9 \times 10^{8} \mathrm{M}^{-1}$ & 19 & - & - & - & 2.9 \\
SM22 & $\gamma 3$ & $7.8 \times 10^{7} \mathrm{M}^{-1}$ & 2.7 & - & - & - & 0.75 \\
SM23 & $\mu$ & $\mathrm{ND}$ & 0.19 & - & - & - & 0.13 \\
SM24 & $\gamma 2 \mathrm{a}$ & $2.5 \times 10^{8} \mathrm{M}^{-1}$ & 14.4 & 12.7 & 0.02 & - & 5.8
\end{tabular}

\section{Table 2. Reactivity of monoclonal antibodies with different gonococcal strains}

Reactivity of strains with monoclonal antibodies was determined by 'dot blotting' of whole-cell lysates onto nitrocellulose followed by reaction with antibody and ${ }^{125}$ I-labelled Protein A. Proteolytic sensitivity was determined after SDS-PAGE of suspensions treated with $\alpha$-chymotrypsin: S, sensitive; $\mathrm{R}$, resistant.

\begin{tabular}{|c|c|c|c|c|c|}
\hline \multirow[b]{2}{*}{ Strain } & \multicolumn{4}{|c|}{ Reactivity with antibody: } & \multirow{2}{*}{$\begin{array}{c}\text { Proteolytic } \\
\text { sensitivity } \\
\text { of P.I }\end{array}$} \\
\hline & SM20 & SM21 & SM22 & SM24 & \\
\hline P9 & + & + & + & + & $\mathbf{S}$ \\
\hline SU72 $(+5$ others $)$ & - & + & + & + & S \\
\hline SU85 ( +6 others) & + & - & - & + & S \\
\hline SU50; SU53 ( +4 others) & - & - & - & + & S \\
\hline SU62; SU70 ( +22 others) & - & - & - & - & $\mathbf{R}$ \\
\hline
\end{tabular}

antibodies showed restricted reactivity on ELISA with OM from four other strains despite the rationale of their production and selection.

The four antibodies of IgG class were further screened by dot blotting against whole-cell lysates of gonococci (44 strains), meningococci (20 strains) and other Gram-negative bacteria including $N$. lactamica and other Neisseria species. The reactivity of all the antibodies was restricted to gonococci; none reacted with any other species tested. Antibody SM24 showed the most extensive cross-reactivity, amounting to $45 \%$ of the gonococcal strains tested. The other antibodies reacted with $<20 \%$ of the strains and only from amongst those which were SM24 positive. Antibodies SM21 and SM22 reacted with identical strains, distinct from those recognized by antibody SM20. It was thus possible to divide the gonococci into five groups according to their pattern of antibody reactivity (Table 2), strain P9 being unique in that it reacted with each.

\section{Classification of P.I by proteolytic sensitivity}

Since gonococcal isolates fall into two roughly equal groups according to the P.I type expressed, the gonococcal strains used above were classified by their expression of P.IA or P.IB as determined by sensitivity to proteolytic digestion (Barrera \& Swanson, 1984). Suspensions were incubated with $\alpha$-chymotrypsin then subjected to SDS-PAGE alongside untreated samples. Two patterns of reactivity were seen (Fig. 1). With one group, which included strain P9, P.I was degraded with the concomitant appearance of fragments of approximate $M_{\mathrm{r}} 22000$, 20000 and 15000 , whereas the other strains were resistant to digestion. When the P.I type was compared to reaction with the monoclonal antibodies, reactivity was only found among members of the P.IB group. Antibody SM24 reacted with all the P.IB-expressing strains which were tested, indicating the presence of a conserved epitope in the different serotypes of P.IB. 


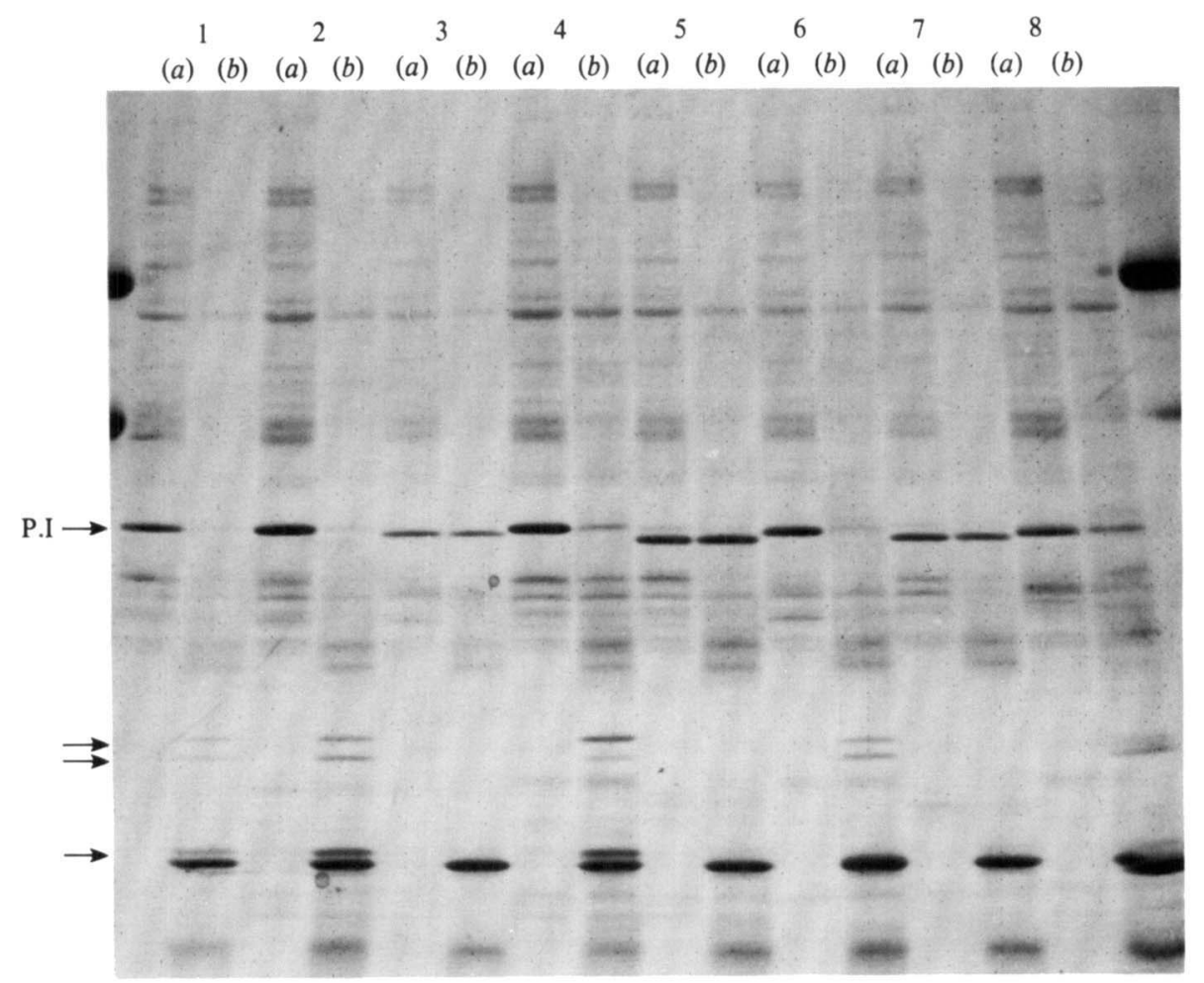

Fig. 1. SDS-PAGE showing sensitivity of P.I to $\alpha$-chymotrypsin cleavage in different gonococcal strains. Whole-cell suspensions were incubated at $37^{\circ} \mathrm{C}(a)$ in the absence of enzyme and $(b)$ in the presence of $125 \mu \mathrm{g} \alpha$-chymotrypsin $\mathrm{ml}^{-1}$. Arrows indicate positions of fragments of $M_{\mathrm{r}} 22000,20000$ and 15000 produced with the sensitive strains 1 (P9), 2 (SU73), 4 (SU81), 6 (SU90) and 8 (SU92). Resistant strains were 3 (SU77), 5 (SU89) and 7 (SU91).

\section{Competitive radioimmunoassay}

In order to investigate the spacial distribution of epitopes on P.IB the antibodies of IgG class were labelled with ${ }^{125}$ I and used in competitive radioimmunoassay. Ascitic fluids were serially diluted and incubated with OM from variant P9-1 before the addition of the predetermined amount of labelled antibody required for saturation binding. ELISA had shown that each ascitic fluid contained greater than saturating levels of antibody at dilutions of $1: 100$.

Under the conditions used the excess of unlabelled antibody present in ascitic fluid at a dilution of $1: 100$ inhibited binding of $70-95 \%$ of the homologous ${ }^{125}$ I-labelled IgG. In most cases the homologous antibody was amongst the most effective inhibitors (Fig. 2) but with SM21 this was not the case; antibodies SM22 and SM24 showed considerably greater effect. With each antibody a significant but variable degree of inhibition of binding was also seen with each of the heterologous antibodies (Fig. 2). Thus antibodies to the other P.IB epitopes all showed inhibition of SM24 binding to the conserved P.IB epitope in the relative order SM22 $>$ SM21 $=$ SM23 $>$ SM20. In contrast to the P.IB antibodies, monoclonal antibodies directed against other OM proteins, namely P.II and a common pathogenic Neisseria protein (Virji et al., 1985), showed no inhibition of SM24 binding and an anti-LPS monoclonal antibody gave limited inhibition only at the highest concentration tested (Fig. 3).

\section{Location of the conserved epitope on peptides derived from P.IB}

OM from variant P9-1 were incubated with $\alpha$-chymotrypsin, samples were periodically withdrawn and subjected to SDS-PAGE. The P.IB band with an apparent $M_{\mathrm{r}}$ of 36000 was gradually reduced in intensity with the concomitant appearance of 15000 and 22000 bands (Fig. $4 a$ ). On prolonged incubation a minor band of $M_{\mathrm{r}} 20000$ was also produced. Western blotting of 


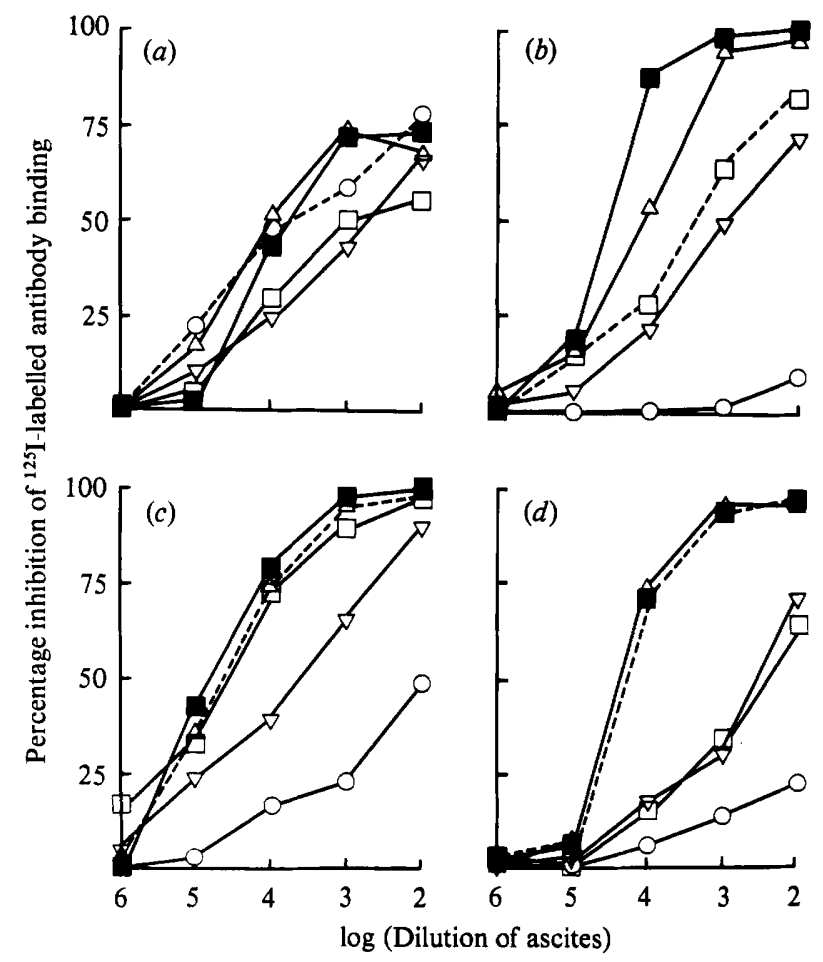

Fig. 2. Competitive radioimmunoassay with ${ }^{125} \mathrm{I}$-labelled anti P.IB monoclonal antibodies. Labelled antibodies were incubated in wells coated with OM from variant P9-1 with increasing concentrations of unlabelled antibody. Labelled antibodies were (a) SM20, (b) SM21, (c) SM22 and (d) SM24; competing

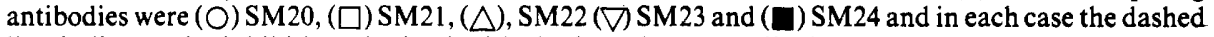
line indicates the inhibition obtained with the homologous antibody.

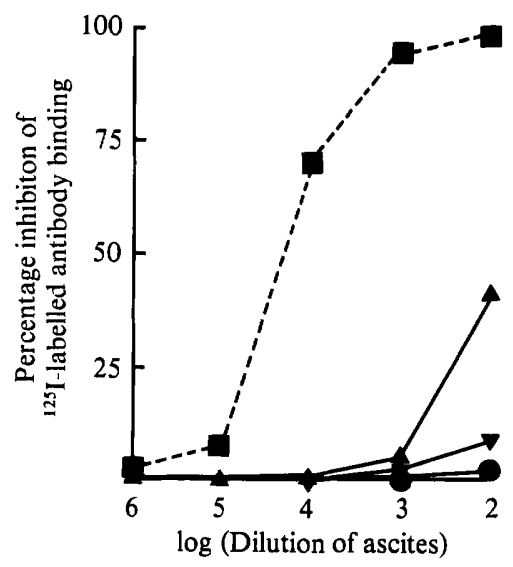

Fig. 3. Effect of monoclonal antibodies to other OM components on binding of antibody to the conserved P.IB epitope. Labelled antibody SM24 was incubated in wells coated with OM from variant P9-16 (containing P.IIb in addition to the antigens expressed by P9-1) in the presence of monoclonal antibodies directed against LPS (SM80, A), P.IIb (SM40, O) and the pathogenic Neisseria-specific protein (SM70, $)$ and the homologous unlabelled SM24 ( $\mathbf{\square})$. 


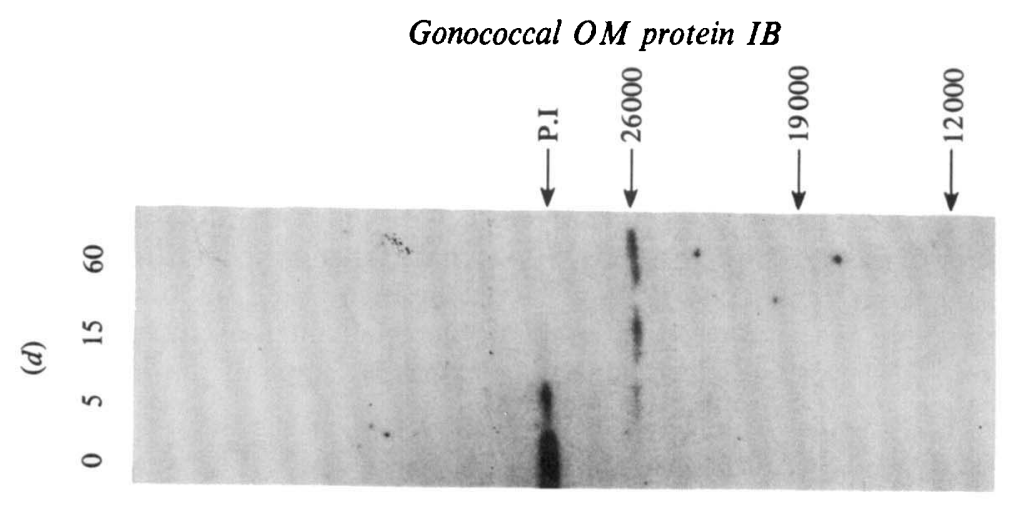

1617

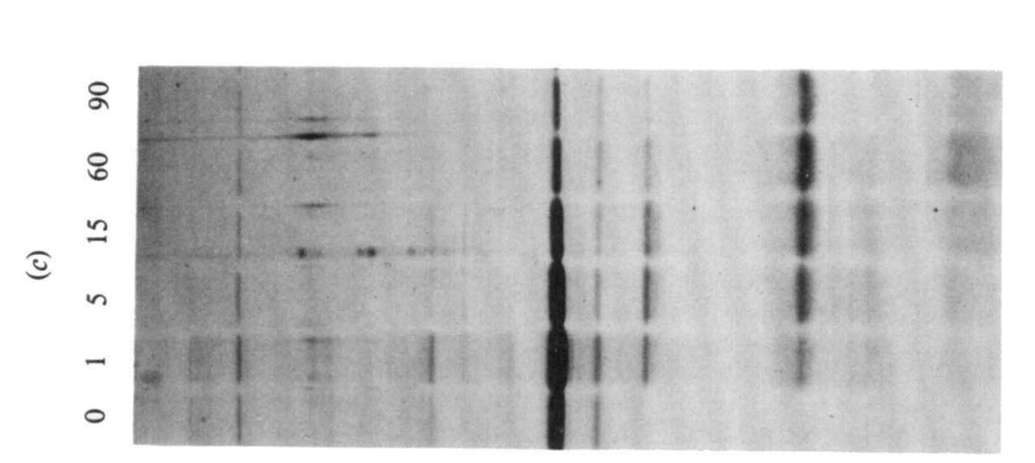

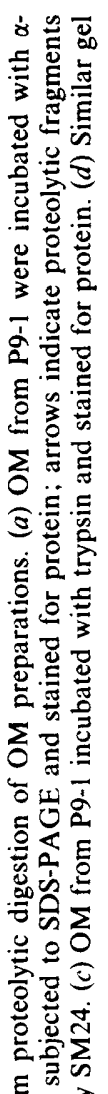

옹

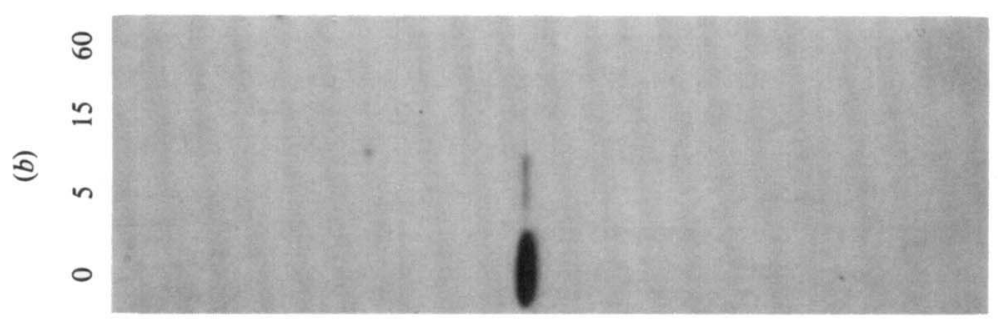

马्छ

过苞.

o

응

宫导志

드의

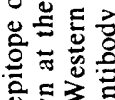

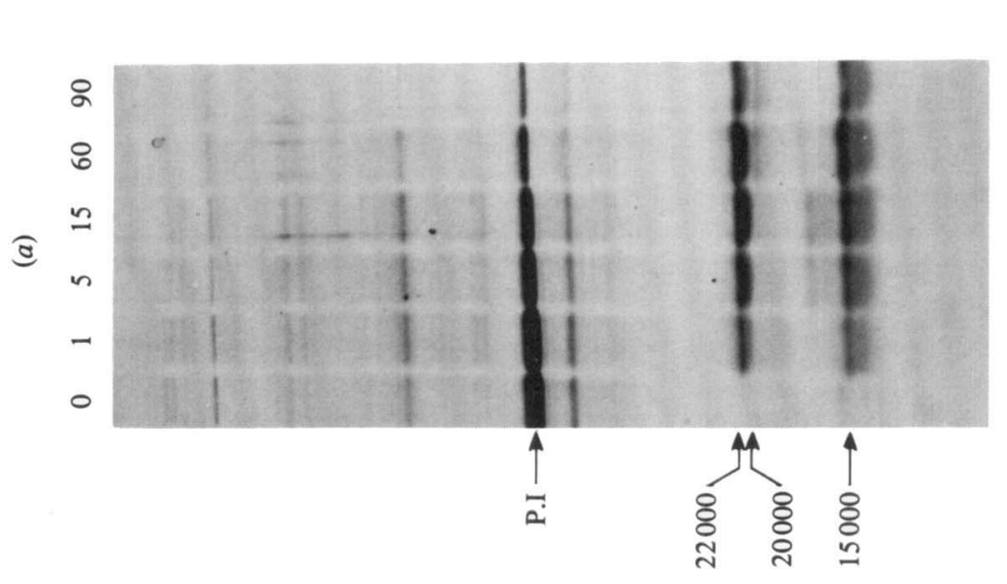

政

똔옹

돌 월

उ

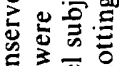

동ㅎㅇ

을

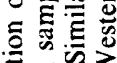

的主

ป



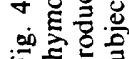


a similar gel with antibody SM24 showed reactivity with P.IB but not with any of the proteolytic fragments (Fig. $4 b$ ).

On incubation of OM with trypsin, P.IB was cleaved to produce fragments of apparent $M_{\mathrm{r}}$ 12000 and 26000 (Fig. 4c). The latter fragment reacted with antibody SM24 but was further cleaved by trypsin to produce a fragment of $M_{\mathrm{r}} 19000$ which failed to react (Fig. $4 d$ ). Both the 12000 and 19000 fragments remained associated with the membrane fraction and were not released into solution. No reactive peptides could be detected in the soluble fraction after Western blotting of SDS-PAGE gels, which had a lower $M_{\mathrm{r}}$ limit of approximately 2000 (Hashimoto et al., 1983).

\section{DISCUSSION}

P.I is the most abundant protein present on the surface of gonococci and appears to play a critical role in maintenance of the structure and function of the OM (Blake \& Gotschlich, 1983). Despite a common functional role variations in the structure of P.I molecules present on different strains are responsible for antigenic differences, which form the basis for a number of serotyping schemes (Sandstrom et al., 1982). Although the object of serological classification is to subdivide gonococci into a relatively large number of types for epidemiological investigations, such studies have generally indicated that the different P.I serotypes fall into one of three main groups, each of which can be further subdivided into a number of serovars. Thus with polyvalent antisera Wang et al. (1977), using immunofluorescence, classified gonococci into three groups, A, B and C, and using co-agglutination Sandstrom \& Danielsson (1980) made the division into groups WI, WII and WIII. In contrast, peptide maps of tryptic or chymotryptic digests of P.I from different strains suggested only two major structural classes (Swanson, 1979). Subsequent studies revealed that serogroup WI strains express one class of P.I (P.IA) and that the WII and WIII groups are closely related and both express P.IB (Sandstrom et al., 1982). The two types of P.I are quite different in their primary structure and organization within the OM. Peptide mapping reveals that, although the different serovars of P.IA have much of their structure in common, as do the different P.IB molecules, there is limited homology between the groups (Sandstrom et al., 1982). Most of the P.IA molecule is contained within the membrane, so resisting proteolytic cleavage, with only a short terminal portion exposed on the surface. In contrast, P.IB molecules have both terminal regions located in the membrane and a central portion exposed on the surface which is susceptible to proteolytic digestion (Barrera \& Swanson, 1984).

The distinct difference between the two classes of P.I is reflected in their reactivity with monoclonal antibodies. A recently described serotyping scheme (Knapp et al., 1984) identified 18 P.IA serovars on the basis of reactivity with one panel of six antibodies, and 28 P.IB serovars from reactivity with a second panel of six. No antigenic cross-reactivity between the two classes was observed. Similarly in the current study none of the monoclonal antibodies, obtained by immunization with OM containing the protease sensitive P.IB, reacted with strains expressing the protease resistant P.IA. Four monoclonal antibodies reacted with epitopes present in a limited number of strains expressing P.IB. Antibody SM24 was of particular interest since it reacted with all the P.IB-expressing strains which were tested, indicating the presence of a highly conserved and perhaps ubiquitous epitope on this protein.

Radioimmunoassay inhibition experiments were done to investigate the proximity of the epitopes recognized. Similar studies with monoclonal antibodies to gonococcal pili have revealed that variable and conserved epitopes lie in distinct domains (Virji \& Heckels, 1983). In addition the similar reciprocal inhibition between pairs of antibodies made it possible to suggest a linear order of epitopes in the variable domain which determines the antigenic specificity of a particular pilus (Heckels \& Virji, 1985). With the P.IB monoclonal antibodies no such conclusions are possible. Each antibody was able to inhibit binding of every other antibody although to a very variable extent and pairs of antibodies did not show similar reciprocal inhibition. Thus, while antibodies SM22 and SM24 both effectively inhibited binding of SM20, this antibody showed only limited inhibition of either SM22 or SM24. The effectiveness of 

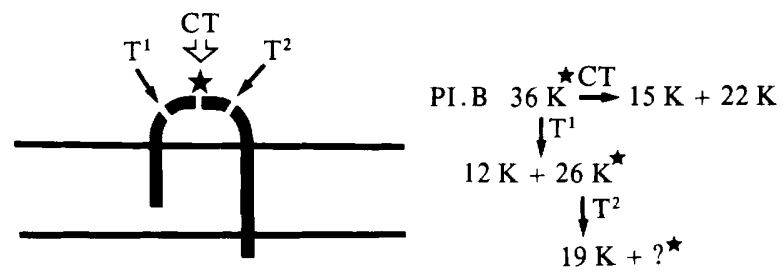

Fig. 5. Location of the conserved epitope on protein IB. Schematic diagram showing orientation of P.IB in the OM (Barrera \& Swanson, 1984) with trypsin (T) and $\alpha$-chymotrypsin (CT) cleavage sites; $\star$ denotes reactivity with antibody SM24; $\mathrm{K}$ denotes $10^{-3} \times M_{\mathrm{r}}$ value.

inhibition did not correlate with avidity of binding, since SM22, the least avid antibody, was amongst the most effective inhibitors. Inhibition data may therefore reveal information about the topography of the epitope distribution, since an antibody binding to a readily accessible epitope would block binding to a more deeply buried epitope but not vice versa. In this model the conserved epitope recognized by SM24 is the most superficially exposed and lies within a variable region containing the other epitopes which determine serotype specificity of P.IB. Another possibility, that binding of one antibody may induce conformational changes affecting binding of a second antibody at a distance, cannot however be excluded.

The location of the conserved epitope within the P.IB molecule could be further determined by Western blotting of peptides generated by treatment of $\mathrm{OM}$ with proteolytic enzymes. Previous studies have revealed that P.IB is cleaved by chymotrypsin to produce two fragments, which remain membrane associated (Blake et al., 1981). While reactivity of SM24 with intact P.IB from strain P9 could be readily detected on Western blots, neither the fragment of $M_{\mathrm{r}}$ 15000 nor the fragment of $M_{\mathrm{r}} 22000$ generated by chymotryptic cleavage reacted. In contrast, the primary site of trypsin cleavage produced a reactive fragment of $M_{\mathrm{r}} 26000$, which was then further cleaved to produce a membrane associated fragment of $M_{\mathrm{r}} 19000$, which failed to react. This cleavage might also be expected to release a soluble fragment of $M_{\mathrm{r}} 7000$ containing the conserved epitope but this could not be detected. Presumably release of the polypeptide from the membrane exposes additional potential trypsin cleavage sites resulting in its further degradation. Using the model of P.IB organization proposed by Barrera \& Swanson (1984) the position of SM24 binding is illustrated in Fig. 5. The conserved epitope is located within a surface exposed region of $M_{\mathrm{r}} 7000$ of the P.IB molecule at or close to the chymotrypsin cleavage site.

The existence of a readily accessible, conserved determinant on a major surface protein provides an attractive target for a potential vaccine. An accompanying paper (Virji et al., 1986) describes the use of monoclonal antibodies to investigate the potential protective effect of antibodies directed against P.IB.

This work was supported by the Medical Research Council.

\section{REFERENCES}

Barrera, O. \& Swanson, J. (1984). Proteins IA and IB exhibit different surface exposures and orientations in the outer membranes of Neisseria gonorrhoeae. Infection and Immunity 44, 565-568.

Blake, M.S. \& Gotschlich, E. C. (1983). Gonococcal membrane proteins: speculation on their role in pathogenesis. Progress in Allergy 33, 298-313.

Blake, M. S., Gotschlich, E. C. \& Swanson, J. (1981). Effects of proteolytic enzymes on the outer membrane proteins of Neisseria gonorrhoeae. Infection and Immunity 33, 212-222.
Diaz, J.-L. \& Heckels, J. E. (1982). Antigenic variation of outer membrane protein II in colonial variants of Neisseria gonorrhoeae P9. Journal of General Microbiology 128, 585-591.

Diaz, J.-L., ViRJ, M. \& Heckels, J. E. (1984). Structural and antigenic differences between two types of meningococcal pili. FEMS Microbiology Letters 21, 181-184.

Douglas, J. T., Lee, M. D. \& Nikaido, H. (1981). Protein I of Neisseria gonorrhoeae outer membrane is a porin. FEMS Microbiology Letters 12, 305-309. 
Frankel, M. E. \& Gerhard, W. (1979). The rapid determination of binding constants for antiviral antibodies by a radioimmunoassay. An analysis of the interaction between hybridoma proteins and influenza virus. Molecular Immunology 16, 101-106.

Hashimoto, F., Horigome, T., Kanabayashi, M., Yoshida, K. \& SUGano, H. (1983). An improved method for separation of low-molecular-weight polypeptides by electrophoresis in sodium dodecyl sulfate-polyacrylamide gel. Analytical Biochemistry 129, 192-199.

HeCKELS, J, E. (1977). The surface properties of Neisseria gonorrhoeae: isolation of the major components of the outer membrane. Journal of General Microbiology 99, 333-341.

HeCKELS, J. E. (1981). Structural comparison of Neisseria gonorrhoeae outer membrane proteins. Journal of Bacteriology 145, 736-742.

HECKELS, J. E. (1986). Gonococcal antigenic variation and pathogenesis. In Antigenic Variation in the Course of Infectious Diseases: a Survival Strategy for Pathogenic Microorganisms. Edited by $\mathrm{H}$. Birkbeck \& C. W. Penn. Cambridge: Cambridge University Press (in the Press).

HeCKelS, J. E. \& VIRJI, M. (1985). Monoclonal antibodies against gonococcal pili : uses in analysis of gonococcal immunochemistry and virulence. In Monoclonal Antibodies Against Bacteria, vol. 1, pp. 135. Edited by A. J. L. Macario \& E. C. de Macario. London: Academic Press.

KNaPP, J. S., TaM, M. R., Nowinski, R. C., Holmes, K. K. \& Sandstrom, E. G. (1984). Serological classification of Neisseria gonorrhoeae with use of monoclonal antibodies to gonococcal outer membrane protein I. Journal of Infectious Diseases 150 , 44-48.

LAMBDEN, P. R. \& HeCKels, J. E. (1982). Synthesis of immunogenic oligosaccharide-protein conjugates from the lipopolysaccharide of Neisseria gonorrhoeae P9. Journal of Immunological Methods 48, 233-240.

Lambden, P. R., HeCkels, J. E., James, L. T. \& WatT, P. J. (1979). Variations in surface protein composition associated with virulence properties in opacity types of Neisseria gonorrhoeae. Journal of General Microbiology 114, 305-312.

Lambden, P. R., Heckels, J. E., McBride, H. \& WATT, P. J. (1981 $a$ ). The identification and isolation of novel pilus types produded by variants of $N$. gonorrhoeae P9 following selection in vivo. FEMS Microbiology Letters 10, 339-341.

LAMbden, P. R., Robertson, J. N. \& WatT, P. J. $(1981 b)$. The preparation and properties of $\alpha$ and $\beta$ pili from variants of Neisseria gonorrhoeae P9. Journal of General Microbiology 124, 109-117.

LynCh, E. C., Blake, M. S., Gotschlich, E. C. \& MaUro, A. (1984). Studies of porins: spontaneously transferred from whole cells and reconstituted from purified proteins of Neisseria gonorrhoeae and Neisseria meningitidis. Biophysical Journal 45, 104-107.

Merril, C. R., Goldman, D., Sedman, S. A. \& EberT, M. H. (1981). Ultrasensitive stain for proteins in polyacrylamide gels shows regional variation in cerebrospinal fluid proteins. Science 211, 1437-1438.
Sandstrom, E. G. \& Danielsson, D. (1980). Serology of Neisseria gonorrhoeae. Classification by co-agglutination. Acta pathologica et microbiologica scandinavica B33, 27-38.

Sandstrom, E. G., Chen, K. C. S. \& Buchanan, T. M. (1982). Serology of Neisseria gonorrhoeae: co-agglutination serogroups WI and WII/III correspond to different outer membrane protein molecules. Infection and Immunity 38, 462-470.

SWANSON, J. (1979). Studies on gonococcus infection. XVIII. ${ }^{125}$ I-labeled peptide mapping of the major protein of the gonococcal cell wall outer membrane. Infection and Immunity 23, 799-810.

Swanson, J., Sparks, E., Young, D. \& King, G. (1975). Studies on gonococcus infection. X. Pili and leukocyte association factor as mediators of interactions between gonococci and eukaryotic cells in vitro. Infection and Immunity 11, 1352-1361.

Towbin, H., Stachelin, T. \& Gordon, J. (1979). Electrophoretic transfer of proteins from acrylamide gels to nitrocellulose sheets: procedure and some applications. Proceedings of the National Academy of Sciences of the United States of America 76, 43504359.

VIRJI, M. \& Everson, J. S. (1981). Comparative virulence of opacity variants of Neisseria gonorrhoeae strain P9. Infection and Immunity 31, 965-970.

VIRJI, M. \& HeCKels, J. E. (1983). Antigenic crossreactivity of Neisseria pili: investigations with typeand species-specific monoclonal antibodies. Journal of General Microbiology 129, 2761-2768.

VIRJI, M. \& HECKELS, J. E. (1986). The effect of protein II and pili on the interaction of Neisseria gonorrhoeae with human polymorphonuclear leucocytes. Journal of General Microbiology 132, 503-512.

ViRJ, M., Heckels, J. E. \& WatT, P. J. (1983). Monoclonal antibodies to gonococcal pili: studies on antigenic determinants on pili from variants of strain P9. Journal of General Microbiology 129, 19651973.

VIRJI, M., ZaK, K. \& Heckels, J. E. (1985). Use of monoclonal antibodies to detect common protein antigens present in outer membranes of Neisseria species. In The Pathogenic Neisseriae, pp. 276-280. Edited by G. K. Schoolnik et al. Washington, DC: American Society for Microbiology.

VIRJ, M., ZAK, K. \& HeCKels, J. E. (1986). Monoclonal antibodies to gonococcal outer membrane protein IB: use in investigation of the potential protective effect of antibodies directed against conserved and type-specific epitopes. Journal of General Microbiology 132, 1621-1629.

Wang, S.-P., Holmes, K. K., KnaPP, J. S., OTT, S. \& KYZER, D. D. (1977). Immunologic classification of Neisseria gonorrhoeae with micro-immunofluorescence. Journal of Immunology 119, 795-803.

ZaK, K., Diaz, J.-L., JaCkson, D. \& Heckels, J. E. (1984). Antigenic variation during infection with Neisseria gonorrhoeae: detection of antibodies to surface proteins in sera of patients with gonorrhea. Journal of Infectious Diseases 149, 166-173. 